\section{Liver Transplantation: Where It's Been and Where It's Going}

Hepatic Carcinoma

Vinod K. Rustgi, M.D., Guest Editor

September 1987

Morbid Obesity II

John G. Kral, M.D., Ph.D., and

Steven B. Heymsfield, M.D., Guest Editors

June 1987

Morbid Obesity I

John G. Kral, M.D., Ph.D., and

Steven B. Heymsfield, M.D., Guest Editors

March 1987

ANORECTAL Disorders

Victor W. Fazio, M.D., M.B.B.S., F.R.A.C.S.,

F.A.C.S., Guest Editor

\section{FORTHCOMING ISSUES}

June 1988

Gasthointestinal Manifestations of AIDS

Scott L. Friedman, M.D., Guest Editor

September 1988

Gastrointestinal Emergencies

Ronald Merrell, M.D., Guest Editor

December 1988

Colorectal Cancer

Gordon Luk, M.D., Guest Editor

March 1989

Inflammatory Bowel Disease

Allen Ginsberg, M.D., Guest Editor
David H. Van Thiel, M.D., Leonard Makowka, M.D., Ph.D., and Thomas E. Starzl, M.D., Ph.D.

The ultimate therapeutic step in the treatment of hepatic disease is the provision of a new liver with or without removal of the affected native organ. At the writing of this manuscript, nearly 2000 liver transplants have been performed in the United States alone. Probably another 1000 have been performed in other parts of the world.

Two approaches to liver transplantation have been utilized. The first consists of the insertion of an extra liver (auxiliary liver transplantation) at an ectopic location. This approach leaves the recipient's diseased liver intact. The alternative approach to auxiliary hepatic transplantation is orthotopic liver transplantation. With this operation, the diseased liver is removed, creating a space into which the allograft is transplanted with as normal an anatomic reconstruction as is possible based upon the specific liver pathology and the prior surgical history of the recipient.

\section{AUXILIARY LIVER TRANSPLANTATION}

The first attempts at whole liver grafting were auxiliary grafts, carried out in $1955 .{ }^{17}, 56$ The use of auxiliary grafts was initially attractive because of the belief that the sacrifice of the residual function of a failing liver could be avoided and would provide some reserve in the event of poor performance on the part of the liver graft. However, the results obtained with auxiliary liver transplantation have been poorer than those obtained with orthotopic liver replacement. The major hypothetical drawback of the auxiliary grafts is that they might atrophy and fail to function with time.

From the University of Pittsburgh School of Medicine, Departments of Medicine and Surgery, Pittsburgh, Pennsylvania

This work was supported in grants NIDDK AM R0132556, NIAAA R0106601 and Program Project AM 29961.

Gastroenterology Clinics of North America-Vol. 17, No. 1, March 1988 
The extent to which this prediction is valid has not been assessed critically because of the many other causes of graft failure in the cases in which it has been attempted. However, it needs to be stated that the placement of extra livers in nonanatomic locations has been difficult historically with a high rate of vascular thromboses and other technical complications being experienced in such cases.

Nevertheless, interest in auxiliary transplantation has stimulated many studies about the fate of liver tissue given different types of portal venous inflow. ${ }^{24,35.43 .48 .49}$ In one such model, splanchnic venous blood is provided to one segment of the liver by way of the portal vein, whereas the other segments are supplied with blood from the inferior vena cava. The segments receiving flow from the vena cava invariably atrophy. Moreover, this atrophy camnot be prevented by arterializing the involved segment. In another model, the so called "double liver," blood returning from the pancreas, duodenum, and stomach passes to one portion of the liver, while the other half of the liver is perfused with venous blood returning from the small intestine. The segment perfused with blood from the upper abdominal viscera remains normal whereas the liver segments perfused with intestinal venous blood will atrophy.

\section{ORTHOTOPIC TRANSPLANTATION}

Since the beginning of the cyclosporine era, more than 1000 patients have received an orthotopic liver transplant. The first reported attempts at orthotopic liver transplantation were by Cannon. Subsequently, orthotopic liver transplantation has been developed principally by United States workers in Denver, Pittsburgh, and English workers in Cambridge and London. ${ }^{7}, 27,29,34,39,40,45,46$ The technical problems associated with orthotopic liver transplantation and the histopathologic features of liver rejection were studied initially in dogs. Subsequently, it was noted that the rejection experienced by orthotopic pig liver homografts was relatively mild as compared with that experienced by the dog

Human orthotopic liver transplantation was first attempted in $1963 .{ }^{36}$ 37,47 At first many people considered transplantation for nonneoplastic disease to be unjustifiable. Later, advanced nonmalignant liver disease became an indication for transplantation only after considerable social and vocational invalidism as a result of hepatic encephalopathy, variceal hemorrhage, hepatorenal syndrome, intractable ascites, and a wide variety of other complications of hepatic disease had occurred. Unfortunately, in many of these early cases, potential recipient deterioration had either already occurred or occurred during the evaluation process or during the time it took to identify an appropriate donor organ. Once begun, hepatic decompensation rapidly leads to coma, anuria, gastrointestinal bleeding, and multiple infections making liver transplantation most difficult, if not impossible.

With continued experience, it became clear that liver transplantation is easier for some hepatic diseases and exceptionally difficult in others. Whatever the underlying hepatic disease might be, however, individuals
Table 1. Indications for Orthotopic Liver Transplantation

\begin{tabular}{cc}
\hline Advanced Chronic Liver Disease & Fulminant Hepatic Failure \\
Predominantly cholestatic diseases & Viral hepatitis \\
Primary biliary cirrhosis & A, B, D, Non-A, Non-B, EBV, Other \\
Primary sclerosing cholangitis & Drug-induced liver disease \\
Biliary atresia & Halothane \\
Familial cholestastic syndromes & Gold \\
Predominantly hepatocellular disease & Disulfiram \\
Chronic viral-induced liver disease & Acetaminophen \\
Chronic drug-induced liver disease & Others \\
Alcoholic liver disease & Metabolic liver disease \\
Idiopathic autoimmune liver disease & Wilson's disease \\
Predominantly vascular disease & Reye's syndrome \\
Budd-Chiari syndrome & Organic acidurias \\
Veno-occlusive disease & Metabolic Liver Disease \\
Hepatic Malignancies That Are Not & Alpha-1 antitrypsin deficiency \\
Resectable & Wilson's disease \\
Hepatocellular carcinoma & Homozygous type II hyperlipoproteinemia \\
Cholangiocarcinoma & Crigler-Najar syndrome type I \\
Rare nonhepatocellular or bile ductular & Erythropoietic protoporphyria \\
tumors that arise within the hepatic & Urea cycle deficiencies \\
parenchyma & Glycogen storage diseases type I and IV \\
Isolated hepatic metastatic disease & Tyrosinemia \\
Carcinoid & Hemochromatosis \\
Pancreatic islet cell tumor & \\
Others & \\
\hline
\end{tabular}

with prior adhesion-forming operations, particularly those in the upper abdomen, have an increased perioperative mortality, especially if the porta hepatis has been dissected for either a portal diversion or a biliary tract reconstructive procedure. ${ }^{38}$

The principal current indications for liver transplantation are shown in Tables 1 and 2. In children, biliary atresia is the leading indication. In adults, postnecrotic cirrhosis has been the most frequent indication. Other diseases in adults for which transplantation has been utilized include primary biliary cirrhosis, sclerosing cholangitis, and a large number of metabolic liver diseases.

In 10 per cent of early operations either a thrombosed or hypoplastic portal vein existed. As a result of this experience, all potential liver transplant candidates currently are studied with ultrasonography to define the status of their portal vein preoperatively. Whenever the results with ultrasonography are either equivocal or consistent with absence of the portal vein, either portal venography as part of a superior mesenteric arteriographic study or an NMR study is obtained to visualize the portal vein. This experience relative to the status of the portal vein as well as experience with other problems encountered has dictated the format of formal pretransplant evaluation for all liver transplant candidates seen at the University of Pittsburgh. The evaluation has the following as its six goals: (1) confirmation of the specific hepatic disease diagnosis; (2) documentation of the disease severity; (3) measurement of the recipient's intellectual and psychiatric status; (4) an assessment of any abnormalities of extrahepatic organ systems that might adversely affect transplantation; (5) a 
Table 2. Clinical and Biochemical Indications for Liver Transplantation Candidacy

Acute Liver Failure

Bilirubin $>10-20 \mathrm{mg} / \mathrm{dl}$ and increasing

Prothrombin time $>10$ seconds above control and increasing

Progressive encephalopathy of at least Grade 3

Chronic Liver Disease

Cholestatic liver disease

Bilirubin > 10-15 mg/dl

Intractable pruritus

Intractable bone disease

Hepatocellular liver disease

Albumin $<2.5 \mathrm{~g} / \mathrm{d}$

Hepatic encephalopathy

Prothrombin time $>5$ seconds above control

Factors common to both types of liver disease

Hepatorenal syndrome

Recurrent spontaneous bacterial peritonitis

Intractable ascites

Recurrent episodes of biliary sepsis

Development of a hepatocellular carcinoma

determination of whether liver replacement is anatomically possible; and finally (6) whether alternative procedure or therapy might not be possible instead of liver transplantation. ${ }^{38,55}$

Because diseased livers due to hepatocellular disease are small, a donor with a smaller liver and therefore of smaller stature $(10 \mathrm{~kg}$ or more less than the recipient) may be sought. This cannot be a generalization, however, as hepatomegaly is characteristic of some hepatic diseases, such as primary biliary cirrhosis and sclerosing cholangitis. Thus, the recipient's liver size should always be estimated with imaging techniques.

Because of the combined effects of coagulopathy and portal hypertension in patients with liver failure, hemostasis is often difficult to obtain until the hypertensive portal venous system is decompressed either through the liver graft or by way of a portal systemic bypass system. Once the new liver is in place, however, improved coagulation can be expected.

The transplant procedure can require large numbers of units of blood in patients with severe portal hypertension. Adhesions present from previous abdominal operations, other than portal-systemic shunts, often create particularly fragile venous collaterals that tend to bleed profusely. If a surgically created portal caval shunt exists, the anastomosis must be taken down to adequately revascularize the graft. In such cases, the residual portal vein is frequently sclerotic and may be difficult to use. When prior portal venous shunting has been accomplished with a functioning mesocaval shunt or splenorenal shunt, the shunt must be closed to prevent a "steal" syndrome that would otherwise deprive the liver graft of its portal venous blood supply. In some cases, a prior shunt will preclude transplantation as a result of retrograde portal vein thrombosis or because the portal vein is rendered abnormal by the aftermath of the diversion.

Transplantation for hepatitis B-induced chronic liver disease has been and continues to be a clinical problem. The antigen titer in the few patients studied has been reduced only temporarily after operation, suggesting that the excised liver is the principal, but not the sole, reservoir for the virus in the body. ${ }^{14}$ Complete clearing of the virus has not been achieved despite treatment with large quantities of hyperimmune globulin. Moreover, course of preoperative immunization with an $\mathrm{HBsAg}$ vaccine has failed also to result in viral clearance either before or after successful transplantation.

\section{CURRENT SPECIFIC INDICATIONS FOR LIVER TRANSPLANTATION}

\section{Biliary Atresia}

The prevalence of biliary atresia has been estimated to be between 1 in 7000 and 1 in 13,000 live births. Most, but not all, children with biliary atresia should be candidates for liver transplantation. ${ }^{10}$ The exceptions are those who have severe associated anomalies of other organ systems that prohibit meaningful life or prohibit transplantation. Such are estimated to occur in about 15 per cent of cases.

All children with biliary atresia need to be evaluated carefully. Some have unexpected intraabdominal venous and intestinal anomalies that either prohibit liver transplantation or make it very difficult. ${ }^{13.41}$ One characteristic cluster of anomalies includes an absent vena cava, a preduodenal portal vein, a hepatic artery arising from the superior mesenteric vein, and intestinal malrotation.

Because of recurrent episodes of cholangitis after a standard porticoenterostomy (Kasai procedure), an increasing number of children with biliary atresia have had multiple abdominal operations, particularly diverting jejunostomies prior to transplantation. These often require closure because of bleeding or stomal ulceration. The net result of such additional surger has been that transplantation becomes more difficult because of the highly vascular adhesions that develop in the hilar area of these children.

\section{Hepatic Malignancy}

The prognosis for patients with a nonfibrolamellar hepatoma that is not resectable without transplantation is highly predictable, with death occurring within 6 months. When first seen, patients with hepatoma may be in good physical condition, and at least some do not deteriorate rapidly while waiting for a donor organ. More importantly, portal hypertension is seldom severe in such cases if the livers do not have cirrhosis. Finally, because livers filled with tumor are either normal in size or more usually enlarged. the technical demands of the surgical procedure per se tend to be simple in comparison to that experienced in individuals with advanced cirrhosis.

Unfortunately, a recurrence of tumor after transplantation is common and has dampened the initial enthusiasm for liver transplantation for this particular indication. 3, 34, 36, 37, 47 Eighty-five per cent of the recipients transplanted in an effort to treat hepatocellular carcinomas, who live long enough for occult residual tumor to be evident, develop overt recurrent 
disease. Moreover, such recurrent disease is the principal cause of death in these recipients. The situation is even worse for those with cholangiolar carcinoma. All such recipients have died of recurrent cholangiolar carcinoma, usually in less than a year. A categorical exclusion of tumor cases based upon this less than ideal experience with hepatic malignancy should not be the rule, however, because primary hepatocellular carcinomas found incidentally in organs removed for cirrhosis have been cured of their malignancy as a result of transplantation. One such patient has been followed postoperatively for more than 18 years.

\section{Postnecrotic Cirrhosis}

Individuals with postnecrotic cirrhosis due to viral, autoimmune, or cryptogenic mechanisms are frequently candidates for liver transplantation, particularly if they have had any of the many complications that presage death in individuals with advanced hepatocellular liver disease, such as spontaneous bacterial peritonitis, hepatorenal syndrome, recurrent varicea bleeding, or they have had recurrent episodes of hepatic encephalopathy or advanced synthetic dysfunction characterized by hypoalbuminemia and coagulopathy. In general, these cases are very difficult technically because of the combination of intense portal hypertension and coagulopathy. Nonetheless, as a group they represent about one third or more of all adult liver transplant cases.

\section{Alpha-1-Antitrypsin Deficiency}

The issues of case selection and surgical technique for this metabolic liver disease are the same as those for patients with postnecrotic cirrhosis, except that care should be taken to perform the transplant prior to the development of irreversible pulmonary disease. After successful operation, the protease inhibitor phenotype of the recipient converts to that of the donor and depressed serum alpha-1-antitrypsin levels become normal.

\section{Other Metabolic Diseases of the Liver}

A metabolic "cure" following liver transplantation either has been proven or presumed in children with type I and IV glycogen storage disease, tyrosinemia, Wilson's disease, and a host of other inborn errors. Most, but not all, of the characteristic metabolic perturbations of these metabolic disorders are corrected after liver transplantation. ${ }^{9,13,18,23,38,58}$

\section{Alcoholic Liver Disease}

Disease of the lungs and a variety of other organs, particularly the brain, are common in alcoholics with endstage liver disease. Following successful transplantation, noncompliance and recidivism can be a problem. Despite these problems, alcoholics have been transplanted and almost all have stayed sober for prolonged periods. A "reasonable" period of alcohol abstinence prior to liver transplantation is a desirable condition but is not essential for transplant candidacy in all alcoholics. Certainly, those alcoholics who adhere to a rehabilitation program and yet fail to regain adequate hepatic function should be offered transplantation.

Despite the many potential social and political issues relative to the wider application of liver transplantation for alcoholic cirrhosis, this indication for liver transplantation is expected to expand. Our view is that alcoholism is a treatable disease, not a vice.

\section{Primary Biliary Cirrhosis (PBC)}

Transplantation for PBC is technically easier to perform than it is for most other indications. The liver is either normal in size or enlarged, venous collaterals are not excessive, and occlusion of the recipient portal vein and vena cava during the anhepatic phase of the procedure mar be well tolerated in such recipients. Recurrences of PBC after successful transplantation have been described, but these claims have not been confirmed. ${ }^{8,11,30,54}$ Thus for the immediate future, PBC will certainly continue to be an important indication for liver transplantation.

\section{Primary Sclerosing Cholangitis (PSC)}

The indications for liver transplantation for PSC are identical to those for PBC, except that many of these patients have had prior biliary tract surgical procedures that make the recipient hepatectomy technically more difficult. ${ }^{25}$ Whether recurrence of the original disease happens in the allograft liver is currently uncertain. Moreover, the role, if any, of the presence of associated inflammatory bowel disease (especially ulcerative colitis) in the development of recurrent disease or even transplant candidacy and the risk of a posttransplant neoplastic disease (colon cancer) are currently unknown.

\section{Secondary Biliary Cirrhosis}

The initiating event in these cases is usually incomplete biliary tract obstruction precipitated as a consequence of a series of unsuccessful attempts at earlier biliary tract reconstruction following one or another complicated biliary tract operation. The technical problems experienced by the transplant surgeons during the procedure can be enormous. These arise both as a result of the altered anatomy and as a result of the numerous adhesions and the portal hypertension that are present. The biliary sepsis present in such cases also increases the surgical risk.

\section{Budd-Chiari Syndrome}

The fact that portal-systemic diversion by decompressing the liver improves hepatic function in some cases and keeps some patients with the Budd-Chiari syndrome away from transplantation creates a dilemma. Many patients with the Budd-Chiari syndrome referred for transplantation will have had a prior side-to-side portal-caval shunting procedure. In such cases. the shunt must be taken down at the time of transplantation. This can be very difficult, frequently requires a portal vein graft, or makes transplantation impossible. Whether portal diversion is ever indicated for BuddChiari syndrome now that liver replacement is a reasonable option is still an open question. 
Table 3. Contraindications for Liver Transplantation

Table 4. Histologic Features that Distinguish Chronic Rejection from

Absolute contraindications

Active sepsis outside the hepatobiliary tree

Metastatic hepatobiliary malignancy

Advanced cardiopulmonary disease

AIDS

Relative contraindications

Advanced chronic renal disease

Age greater than 60 years

Portal vein thrombosis

Cholangiocarcinom

Hypoxemia with intrapulmonary right to left shunts

$\mathrm{HBgAg}$ and $\mathrm{HBeAg}$ positivity

Prior portacaval shunting procedure

Prior complex hepatobiliary surgery

HIV positivity without clinical AIDS

\section{CONTRAINDICATIONS TO LIVER TRANSPLANTATION}

The current list of contraindications for liver transplantation is shown in Table 3. None of these is absolute, although they may be very powerful. For example, preexisting systemic or local infections create highly unfavorable conditions, as do diseases of organs other than the liver, such as coexisting severe heart disease or a history of sociopathic behavior (e.g., alcoholism or drug abuse).

\section{ORGAN PROCUREMENT AND PRESERVATION}

In most transplantation centers in the United States, the criteria of brain death based on the concept of irreversible brain injury have been accepted. Under these conditions and with an ideal cadaveric donor, the interval of normothermic ischemic injury is reduced essentially to zero. Fortunately, public acceptance of these conditions of organ removal has been widespread. Advances have been made in the field of multiple organ harvesting also.

Donor cardiovascular instability, a need for excessive vasopressor support, a long period (several days) between initial injury and the pronouncement of brain death or deterioration of renal function can suggest that the donor organs may be less than ideal as allografts. Another common explanation for poor liver graft function is either inadequate preservation or preexisting hepatic disease. The former is becoming less of a problem as a result of the use of the University of Wisconsin's organ preservation solution. The latter is also becoming less common as a result of better screening of potential donors.

Assuming that donor selection is appropriate, the surgical removal of a good donor organ for transplantation depends upon performing a technically perfect operation that includes recognizing any of the numerous anomalies of the hepatic arterial supply and avoiding warm ischemia. The first of these requirements is dependent on the knowledge and skill of the Recurrent Primary Biliary Cirrhosis

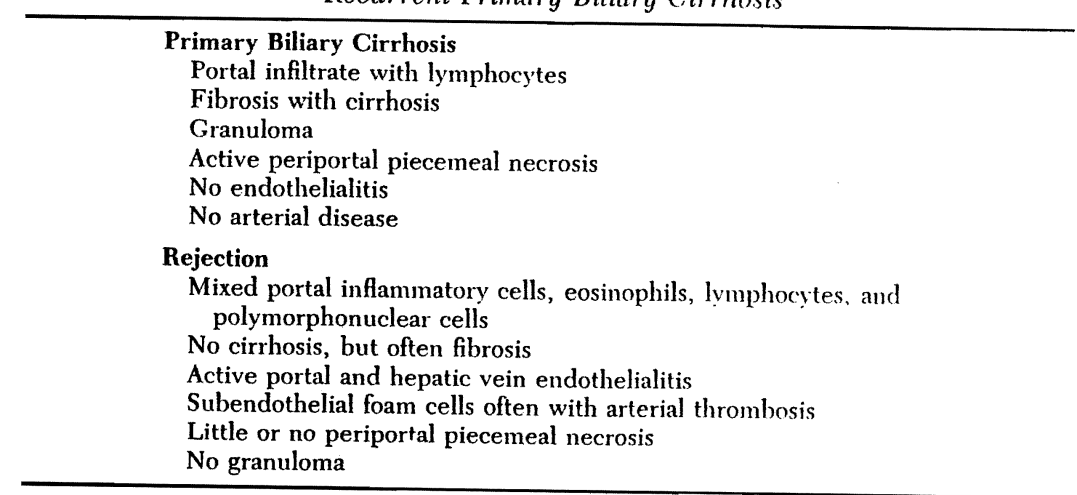

surgeon. The second is also surgeon dependent and can be met by avoiding occlusion of the blood supply during the dissection. The maximum cold ischemia time that still allows predictable and adequate graft function using the recently developed University of Wisconsin liver perfusate solution is probably well beyond 12 hours and closer to 24 hours.

\section{TISSUE MATCHING AND LIVER TRANSPLANTATION}

Waiting for a good match at the A, B, and DR loci of the MHC complex is currently not practical and probably will never be practical for liver transplantation because of the precarious medical condition most liver transplant recipients are in prior to transplantation. It is of some interes that hepatic transplantation has been performed by both the Pittsburgh group and the Cambridge-King's College team despite a positive cytotoxic cross-match., 6, 16, 20, 51, 53 Hyperacute rejection of the grafted liver has eithe not been seen or is markedly reduced in severity as compared to that seen with renal grafts. In animal models of liver transplantation in which the recipient has performed heterospecific cytotoxic humoral antibodies, antibody-initiated rejection of the liver has been reported, but it occurs at much slower rate than it does with the kidney or heart (Table 4). ${ }^{51}$ The mechanisms responsible for graft destruction in ABO-incompatible liver transplants are not well understood, but it seems certain that antigraf isoagglutinins play a role in accelerated if not hyperacute rejections. The reasons why such grafts can be used despite positive cytotoxic cross matches and without a clinical episode of hyperacute rejection remains to he explained.

\section{RECIPIENT PREPARATION AND THE TRANSPLANT PROCEDURE}

Paracentesis and/or thoracentesis are frequently required before general anesthesia in liver transplant recipients. Transfusions of blood and 
albumin are often useful. If fresh whole blood, fresh frozen plasma, or platelets are given, improvement in the preoperative coagulation status of the recipient is usually possible preoperatively.

\section{PORTAL VENOUS BYPASS AND LIVER TRANSPLANTATION}

Usually portal and vena caval occlusion can be tolerated during the 45- to 90-minute anhepatic phase of the operation despite major reductions in the cardiac output and the obligate hypotension that follows portal vein and vena caval clamping. ${ }^{57}$ The ease at which these vessels can be occluded has been shown to be dependent upon the degree of collateral circulation that has developed and allows venous return to occur despite large vessel occlusion. If severe hypotension occurs when cross-clamping either of these vessels, a bypass system must be used. ${ }^{4}, 31$

The fact that most patients can survive portal and inferior vena caval cross-clamping has created an impression that this practice is safe. When portal cross-clamping is performed without a bypass, the intestine becomes progressively boggy and edematous and tends to weep into the peritoneal cavity. Subsequently, the recipient often suffers from third space fluid losses and peritoneal contamination with the development of enteric bacterial and fungal infections. It is easy to imagine how the kidneys can be damaged by occluding the vena cava. The extent to which any one of these complex physiologic events contributes to the high perioperative mortality of liver transplantation has not been delineated until recently. With the routine use of a "heparin free" venous bypass system, the transplant operation can be performed under controlled circumstances and the rate at which a variety of postoperative complications are experienced is reduced dramatically. As a result, patient survival is increased. The venovenous bypass has changed the technical strategy of liver transplantation in several other important ways. In the past, when time was a critical factor during the anhepatic phase, it was often impossible to obtain meticulous hemostasis. When the venovenous bypass is used, hemostatic techniques can be applied and by doing so, most bleeding can be controlled. Moreover, the use of a venous bypass system results in improved intraoperative cardiovascular stability, preservation of renal function by avoidance of renal vein hypertension, excessive blood loss, and subsequent infections.

\section{OPERATIVE PROBLEMS}

\section{Inadequate Recipient Artery}

Hepatic transplant surgeons must be ready to use arterial grafts should the recipient hepatic artery be either too small or inconveniently located to permit an adequate anastomosis. The easiest solution to such problems is to rearterialize the homograft from the recipient's abdominal aorta inferior to the origin of the renal arteries. The extra length of vessel required to reach this location can be obtained most easily by using the donor common iliac artery after ligating the hypogastric artery.

\section{Portal Vein Problems}

If portal venous thrombosis, sclerosis, or hypoplasia is present and involves the splenic and superior mesenteric veins, the confluence of these veins must be dissected free from the pancreas. A cloaca can be created at this junction to which an iliac vein graft can be anastomosed to provide the added length required to reach the homograft portal vein. Without such venous grafts, patients would die in the operating room.

\section{Biliary Tract Reconstruction}

Many of the technical complications experienced in the early davs of liver transplantation were associated with biliary tract recoustruction. Often these complications were not recognized until quite late in the postoperative course. As a result, they were associated with abscess formation, cholangitis, and other forms of hepatic sepsis that contributed directly to the death of patients. Our current practice is to create a choledochocholedochal anastomosis, or if prior biliary tract surgery has been performed, a Roux-en-I choledochojejunostomy. The homograft common duct should be cut high enough so that its distal end is well arterialized from the liver. Anatomic studies have shown that the blood supply to the graft bile duct is dependent upon retrograde perfusion from hilar vessels. Late intra- and extrahepatic biliary strictures are common if the arterial blood supply is not
adequate. ${ }^{26,52}$

\section{Other Operative Problems}

Coagulation defects must be anticipated in all cases. The bleeding experienced intraoperatively can be aggravated by fibrinolysis. Fibrinolysis is a nonspecific finding that can be caused by ischemic injury of the graft, or it may represent a manifestation of humoral rejection. Bleeding control starts with suture ligation and cautery. With the new liver in place. the portal system can be decompressed through the new organ, eliminating portal hypertension as an additional contributing factor for the bleeding. Meanwhile, platelets, fresh frozen plasma, and blood constituents should be transfused as necessary.

\section{LATE POSTOPERATIVE PROBLEMS}

\section{Major Problems}

The list of late complications includes peritonitis with or without bowel infarction, bile leaks and/or biliary obstruction, pancreatitis, pulmonars emboli, extraabdominal infections, and psychosis. The most important issue for recipient survival is the ability to control rejection. Currently, the combination of cyclosporine with steroids is the most commonly used immunosuppressive regimen. Adjuvants to this combination include antilymphocyte or antithymocyte globulins (ALG or ATG) and, more recently. monoclonal antithymocyte globulin $\left(\mathrm{OKT}_{3}\right)$.

Nephrotoxicity is the most serious side effect of cyclosporine use Fortunately, the renal dysfunction seen with cyclosporine usually can be 
reversed with appropriate reduction of the dose. Gum hyperplasia, tremor, hirsutism, regional flushing, vague abdominal discomfort, seizures, and the development of breast fibroadenomas are other known side effects. Although hepatotoxicity has been reported, this untoward effect of cyclosporine has rarely been serious in liver transplant recipients and can be controlled by dose reduction when it occurs. ${ }^{22}$

A disturbing consequence of immunosuppression with any first line agent, including cyclosporine, has been the development of an EBV-related lymphoproliferative syndrome and lymphoma. ${ }^{32}$ In kidney recipients, the risk has been almost the same after the introduction of cyclosporine as before. In contrast, the risk of de novo epithelial malignancies with cyclosporine may be less than that experienced with previously used conventional immunosuppressive regimens and, as yet, very few such tumors have been reported in cyclosporine-treated patients. ${ }^{32}$

The first sign of rejection histopathologically in human recipients is the occurrence within the liver of lymphoblastoid cells that appear to leave the smallest portal vessels throughout the graft and accumulate in the portal tracts beneath the endothelial lining of the sinusoids. As a result of this cellular infiltration, the sinusoids became progressively narrowed and occasionally occluded. As a result, blood flow through the liver can decrease with the development of centrilobular ischemia and occasionally necrosis ${ }^{12}$ ${ }^{19,}{ }^{33}$ In severe cases, this centrilobular necrosis can progress to midzonal necrosis, and biochemical liver function rapidly deteriorates.

Marked centrilobular cholestasis and canalicular cholestasis can occur also. A precise pathophysiologic explanation for this cholestasis has not yet been established, but it is almost certainly a manifestation of rejection. With chronic rejection, the intralobular bile ducts vanish. ${ }^{12}$, 33 Fibrosis develops and can progress to a true portal cirrhosis in some cases. A characteristic feature of the chronic rejection process is intimal and subintimal vascular thickening. Hepatic blood flow is reduced in cases with severe rejection, making the ischemic liver graft potentially susceptible to bacterial invasion. $2,15,42$

Currently the clinical diagnosis of chronic rejection is restricted to those patients whose graft biopsies demonstrate either arterial intimal thickening, hepatic fibrosis, or bile duct paucity. The morphologic findings of "chronic" rejection are not related directly to the postoperative interval and can be seen within the first few postoperative months. The clinical manifestations of chronic rejection are similar to those of chronic liver failure from any cause. In contrast to the process of "acute" hepatic rejection, "chronic" rejection does not respond to increased immunosuppression.

\section{Causes of Post-Liver Transplantation Mortality}

The greatest mortality experienced after liver transplantation occurs early, usually within the first few months following the procedure. This has been both with liver transplantation under conventional immunosuppression and with cyclosporine-steroid regimens. Detailed analyses of the causes for this early mortality have been published. The dominant pathologic diagnoses in grafts that fail are rejection, biliary obstruction, recurrent carcinoma, HBV infection, and recurrent original disease occurring less often. ${ }^{2,12}$

The time at which changes in current postoperative management are most likely to produce a substantial reduction in future mortalit- figures is during the immediate perioperative period.

\section{Retransplantation}

When a transplanted liver fails, aggressive attempts at retransplantation offer the only chance for survival. One of the most commonly seen judgment errors in liver transplantation has been to attempt to gain improvement in hepatic function with greater and greater degrees of immunosuppression until the chance for retransplantation is lost as a result of sepsis. Retransplantation, when performed early, is surprisingly easy to do. The procedure is greatly simplified by retaining vascular cuffs from the supra- and infrahepatic vena cavae and less commonly from the portal vein of the failing graft. Total retransplantation operative time can be as little as 3 to 4 hours, if the primary operation has been recent.

\section{FACTORS THAT AFFECT SURVIVAL}

Certain risk factors have been examined for their effect on survival. Among the more important factors has been age. Pediatric recipients throughout the entire history of liver transplantation have fared better by a few percentage points than have adults. Two high-risk diseases in adults have been identified. Specifically survival with postnecrotic cirrhosis and with primary hepatic tumors is less than it is for any other indication. With cirrhosis, the principal problems have been the numerous surgical difficulties caused by the pathologic process (coagulopathy and portal hypertension), the poor condition of the cirrhotic patient, and the universal return of the original B-virus-induced disease in HBV carriers. In patients with primary hepatic malignancy the early mortality is low, with more than 80 per cent of the recipients alive at 6 months. Unfortunately a steady decline occurs thereafter as a result of recurrent tumor.

\section{WHERE ARE WE GOING?}

The future of liver transplantation is bright. Clearly as a result of increasing experience, concept development and the formation of principles of liver disease development, progression and therapy are to be expected. Currently, it is generally believed that specific liver diseases require specific therapies. In the future, subtypes of one or another complication of liver disease, such as hepatic encephalopathy, will require specific and different therapeutic modalities. Crisis management in the field of liver clisease has been and will continue to be replaced by carefully thought out and selected therapies that will be initiated not in response to, but in an effort to prevent the development of a complication of liver disease. Nowhere would the potential for prophylaxis be greater than in alcoholics or in B virus carriers. 
Such developments should lead to fewer transplants being performed for end stage liver disease and more being performed for selected indications. As the clinical arena of liver disease shifts from crisis management to disease control and the application of specific therapies for specific indications, one or more artificial "livers," which perform one or more "hepatic functions" will be developed. As a result, liver transplantation for fulminant hepatic failure will be utilized less often, but will be applied more frequently for the problem of subacute hepatic failure in patients who have "flunked" a trial of interim support.

It should be noted that liver transplantation not only provides physicians and surgeons with challenges, but it has also provided them with the tools to address these challenges. Specifically, liver transplantation centers inevitably will become centers of excellence in the knowledge of hepatic disease. As a result, patients with liver disease will either seek out or be referred to such centers. Thus the epidemiology and natural history of poorly defined and as yet unrecognized liver diseases will be identified throughout their entire course. The removed organs will provide tissues, cells, viruses, DNA, and other materials and agents that are responsible for or that modify the liver disease. Patients with new organs and on immunosuppressive agents will develop old diseases with new faces as well as totally new diseases.

Issues relative to hepatic disease complication progression and/or reversal following liver transplantation will be addressed. Similarly the important issue of disease recurrence in a new organ will be addressed. What forces produce these diseases or modify their presentation, when and if they recur, will be identified and studied. The information gained wil provide new insights into the specific pathogenesis of individual liver diseases and their complications.

Concerning the issue of disease recurrence, we already know that certain diseases such as the Budd-Chiari syndrome, hepatocellular carcinoma, and cholangiolar cancer as well as hepatitis B virus positive (DNA +) disease reoccur in the allograft. Does NANB hepatic disease reoccur as well? Do primary biliary cirrhosis and primary sclerosing cholangitis reoccur? Does autoimmune chronic active hepatitis reoccur? These questions remain very difficult to answer for even the committed hepatologist, transplant surgeon, and hepatic pathologist. The reason for this marked difference in perspective is that these types of physicians recognize the problems of specific liver disease identification based upon presently used standards. Currently only a few liver diseases are diagnosed, utilizing the identification of a specific agent or enzyme defect and have a characteristic histopathology and/or clinical course. These diseases can be said to be iclentified utilizing a gold standard. Many more liver diseases are recognized as a result of a silver standard, which involves a characteristic and unique but not pathognomonic pathology that is often associated with characteristic and unique serologic responses. Unfortunately, no specific agent or pathophysiologic mechanism of disease has been recognized in these cases. Even more discouraging, however, is the fact that many more liver diseases are identified utilizing a copper standard. That is, they have a characteristic but not unique pathology and no characteristic serologic or biochemical markers. Clearly, utilizing anything but a gold standard makes the recognition of disease recurrence, as distinct from the development of a new disease in a new organ, difficult, if not impossible

Additional questions that will be answered as a result of the increasing experience with liver transplantation include the following. (1) Why do liver rejection and chronic active hepatitis differ so markedly histopathologically when the mechanisms involved appear to be so similar and dependent upon an active T cell-dependent immune response? (2) What is the role of cell surface and intracellular organelle antigens in liver disease initiation, progression, perpetuation, and possibly disease recurrence?

It is expected that new and better methods of rejection control and hopefully prevention (tolerance) will be developed. These will inclucle methods or techniques of modulating antigen-processing cells (APC cells) and suppressor cell numbers, function, and lymphokine modulation/neutralization.

An alternative to enhanced prevention or control of rejection will be methods and techniques of initiating, modulating, and selectivelv regulating hepatocyte and bile ductular cell regeneration. Should controlled regeneration be possible, at a rate that equals the losses due to rejection, a new and entirely different state of, or concept of, "tolerance" will develop.

The knowledge that evolves from attempts to achieve these goals in the clinical arena of liver transplantation will be applied also to the problem of fulminant hepatic failure. Growth factors or regeneration modulators will be developed and used in patients with this lethal problem. As a result, the number of transplantations for fulminant hepatic failure will be rednced and the number of such patients recovering without the need for transplantation (new successes) as well as the number operated upon for subacute hepatic failure (persistent therapy failures) will increase. Fortumately, the number of the latter will be reduced markedly from that which currently. pertains.

Finally the organs removed at the time of transplantation will provide the necessary raw materials for the preparation, characterization, and probable ex-vivo production of somatomedins, osteocalcins, and many other materials that will be used to treat and/or prevent complications, such as growth failure and bone disease, that currently characterize patients with advanced liver disease.

Clearly much has been learned from the past. Much continues to be done. However, the future is promising.

\section{REFERENCE}

1. Birtch AG, Orr WM, Duquella J: Evaluation of horse antidog antilymphocyte ghobulin in the treatment of hepatic allografts. Surg Forum 19:186-188. 1968

2. Brettschneider L, Tong JL, Boose DS, et al: Specific bacteriologic problems with canine orthotopic liver transplantation. Arch Surg 97:313-322, 1968

3. Calne RY: Liver transplantation for liver cancer. World J Surg 6:76-80, 1982

4. Calne RY, Williams R: Liver transplantation. Curr Probl Surg 16:3-44, 1979

5. Calne RY, Williams R: Orthotopic liver transplantation: The first 60 patients. Br Med ] $1: 471-476,1977$ 
6. Calne RY, McMaster P, Portmann B, et al: Observations on preservation, bile drainage and rejection. Ann Surg 186:282-290, 1977

7. Cannon JA: Transplant Bull 3:7, 195

Demetris AJ, Markus BH, Esquivel C: Pathologic analysis of liver transplantation for primary biliary cirrhosis. Hepatology (In press)

. DuBois RS, Giles G, Rodgerson DO, et al: Orthotopic liver transplantation for Wilson's disease. Lancet 1:505-508, 1971

10. Eck NV: K. Voprosu o perevyazkie vorotnois veni. Predvaritelnoye soolshtshjenye (Ligature of the portal vein). Voen Med J (St. Petersburg) 130:1-2, 1877 (English translation provided by Child CG III. Surg Gynecol Obstet 96:375-376, 1953

11. Esquivel CO, Bernardos A, Demetris AJ, et al: Liver transplantation for primary biliary cirrhosis. Gastroenterology (In press)

12. Fennell RH, Roddy HJ: Liver transplantation: The pathologist's perspective. Pathol Ann 2:155-182, 1979

13. Fisch RO, McCabe ERB, Doeden D, et al: Homotransplantation of the liver in a patient with hepatoma in hereditary tyrosinemia. J Pediatr 93:592-596, 1978

14. Fortner JG, Yeh SDJ, Kim DK, et al: The case for and technique of heterotopic liver grafting. Transplant Proc 11:269-275, 1979

15. Fulginiti VA, Schibner R, Groth CG, et al: Infections in recipients of liver homografts. N Engl J Med 279:619-626, 1968

16. Giles GR, Boehmig HJ, Lilly J, et al: The mechanism and modification of rejection of heterografts between divergent species. Transplant Proc 2:522-537, 1971

17. Goodrich EO, Welch HF, Nelson JA, et al: Homotransplantation of the canine liver. Surgery 39:244-251, 1956

18. Groth CG, Dubois RS, Corman J, et al: Metabolic effects of hepatic replacement in Wilson's disease. Transplant Proc 5:829-833, 1973

19. Groth CG, Porter KA, Otte JB, et al: Studies of blood flow and ultrastructural changes in rejection and nonrejection canine orthotopic liver homografts. Surgery 63:658-668, 1968

20. Iwatsuki S, Iwaki $\mathrm{Y}$, Kano $\mathrm{T}$, et al: Successful liver transplantation from cross match positive donors. Transplant Proc 13:286-288, 1981

21. Iwatsuki S, Klintmalm GBG, Starzl TE: Total hepatectomy and liver replacement (orthotopic liver transplantation) for primary hepatic malignancy. World J Surg 6:8185,1982

22. Klintmalm GBG, Iwatsuki S, Starzl TE. Cyclosporin A hepatotoxicity in 66 renal allograft recipients. Transplantation 32:488-489, 1981

23. Malatack JJ, Finegold DN, Iwatsuki S, et al: Liver transplantation for type I glycogen storage disease. Lancet 1:1073-1076, 1983

24. Marchioro TL, Porter KA, Brown BI, et al: The effect of partial portacaval transposition on the canine liver. Surgery $61: 723-732,1967$

25. Marsh JW, Iwatsuki S, Makowka L, et al: Orthotopic liver transplantation for primary sclerosing cholangitis. Annals Surgery 207:21-28, 1988

26. Martineau G, Porter KA, Corman J, et al: Delayed biliary duct obstruction after orthotopic liver transplantation. Surgery 72:605-610, 1972

27. Mikaeloff P, Dureau G, Rassat JP, et al: Orthotopic transplantation of the liver in dogs. II. Immunosuppressive treatment (Imuran and Actinomycin C). Ann Chir Thorac Cardiovasc 4:649-662, 1965

28. Mikaeloff P, Pichlmavr R, Rassat JP, et al: Orthotopic homotransplantation of the liver in the dog: Immunosuppressive treatment with antilymphocyte serum. Presse Med 75:1967-1970, 1967

29. Moore FD, Wheeler HB, Demissianos HV, et al: Experimental whole-organ transplantation of the liver and of the spleen. Ann Surg 152:374-387, 1960

30. Neuberger J, Portmann B, Macdougall BR, et al: Recurrence of primary biliary cirrhosis after liver transplantation. $\mathrm{N}$ Engl J Med 306:1-4, 1982

31. Papas G, Palmer WM, Martineau GL, et al: Hemodynamic alterations caused during orthotopic liver transplantation in humans. Surgery $70: 872-875,1971$
32. Penn I: Tumor incidence in human allograft recipients. Transplant Proc 11:104i-1051, 1979

33. Porter KA: Pathology of liver transplantation. Transplant Rev 2:129-170, 1969

34. Starzl TE (with the assistance of CW Putnam): Experience in hepatic transplantation Philadelphia, WB Saunders, 1969, p 163-188

35. Starzl TE, Francavilla A, Halgrimson CG, et al: The origin, hormonal nature, and action of hepatotrophic substances in portal venous blood. Surg Gynecol Obstet 137:179-199.

36. Starzl TE, Groth CG, Brettschneider L, et al: Orthotopic homotransplantation of the human liver. Ann Surg 168:392-415, 1968

37. Starzl TE, Groth CG, Brettschneider L, et al: Extended survival in three cases of orthotopic homotransplantation of the human liver. Surgery 63:549-563, 1968

38. Starzl TE, Iwatsuki S, Van Thiel DH, et al: Evolution of liver transplantation. Hepatolog 2:614-636, 1982

39. Starzl TE, Kaupp HA, Brock DR, et al: Reconstructive problems in canine liver homotransplantation with special reference to the postoperative role of hepatic venous flow. Surg Gynecol Obstet 111:733-743, 1960

40. Starzl TE, Kaupp HA, Brock DR, et al: Studies of the rejection of the transplanted homologous dog liver. Surg Gynecol Obstet 112:135-144, 1961

41. Starzl TE, Koep LJ, Halgrimson CG, et al: Fifteen years of clinical liver transplantation. Gastroenterology 77:375-388, 1979

42. Starzl TE, Koep LJ, Porter KA, et al: Decline in survival after liver transplantation. Arch Surg 115:815-819, 1980

43. Starzl TE, Lee I-Y, Porter KA, et al: The influence of portal blood upon lipid metabolism in normal and diabetic dogs and baboons. Surg Gynecol Obstet 140:381-396, 1975

44. Starzl TE, Marchioro TL, Porter KA, et al: The use of heterologous antilymphoid agents in canine renal and liver homotransplantation and in human renal homotransplantation. Surg Gynecol Obstet 124:301-318, 1967

45. Starzl TE, Marchioro TL, Porter KA, et al: Factors determining short- and long-term survival after orthotopic liver homotransplantation in the dog. Surgery 58:131-1.55. 1965

46. Starzl TE, Marchioro TL, Rais TD, et al: Avenues of future research in homotransplantation of the liver: With particular reference to hepatic supporting procedures, antilymphocyte serum, and tissue typing. Am J Surg 112:391-400, 1966

47. Starzl TE, Marchioro TL, von Kaulla K, et al: Homotransplantation of the liver in humans. Surg Gynecol Obstet 117:659-676, 1963

48. Starzl TE, Porter KA, Kashiwagi N, et al: The effect of diabetes mellitus on portal blood hepatotrophic factors in dogs. Surg Gynecol Obstet 140:549-562, 1975

49. Starzl TE, Porter KA, Kashiwagi N, et al: Portal hepatotrophic factors, diabetes mellitus, and acute liver atrophy, hypertrophy and regeneration. Surg Gynecol Obstet 141:84:3858,1975

50. Starzl TE, Porter KA, Putnam CW: Eleven and two-thirds years survival after canine orthotopic liver transplantation. Transplantation 23:168-171, 1977

51. Starzl TE, Porter KA, Putnam CW, et al: Orthotopic liver transplantation in 9.3 patients. Surg Gynecol Obstet 142:487-505, 1976

52. Starzl TE, Putnam CW, Hansbrough JF, et al: Biliary complications after liver transplantation; with special reference to the biliary cast syndrome and techniques of secondary duct repair. Surgery 81:212-221, 1976

53. Starzl TE, Putnam CW, Ishikawa M, et al: Current policies in hepatic tramsplantation: Candidacy of patients with alcoholic liver disease or preformed antidonor antibodies and a reappraisal of biliary duct reconstruction. NY Acad Sci 252:145-158, 1975

54. Van Thiel DH, Gavaler JS: Recurrent disease in patients with liver transplantation: When does it occur and how can we be sure? Hepatology $7: 181-184,1987$

55. Van Thiel DH Schade RR, Starzl TE, et al: Liver transplantation in adults. Hepatolog: 2:637-640, 1982

56. Welch CS: A note on transplantation of the whole liver in dogs. Transplant Bull 2:54-55. 1955 
57. Williams R, Smith M, Shilkin KB, et al: Liver transplantation in man: The frequency of rejection, biliary tract complications, and recurrence of malignancy based on an analysi of 26 cases. Gastroenterology 64:1026-1048, 1973

58. Zitelli BJ, Malatack JJ, Gartner JC, et al: Orthotopic liver transplantation in children with hepatic-based metabolic disease. Transplant Proc 15:1284-1287, 1983

1000J Scaile Hall

University of Pittsburgh

School of Medicine

Pittsburgh, Pennsylvania 15261

\section{Medical Problems Before and After Transplantation}

Vincent J. Dindzans, M.D., Robert R. Schade, M.D. and David H. Van Thicl, M.D.

Orthotopic liver transplantation has gained acceptance as the only effective treatment for patients with advanced liver disease of any etiology. ${ }^{26}$ This has occurred largely as the result of improvements in immunosuppression, the surgical technique, and experience. Currently liver transplantation is being performed by many surgeons in many different medical centers.

By definition, candidates for liver transplantation are victims of severe liver disease who have experienced many of the medical complications of chronic advanced disease. Often they have multiple organ srstem failure. Immediately posttransplantation, these patients are subject to the many complications of a major surgical procedure (liver transplantation) as weil as the consequences of their resolving preoperative medical problems, many of which may be exacerbated at least temporarily by the surgical procedure. Finally both of these events occur in the presence of immunosuppression.

The purpose of this article is to first review the medical complications that can occur in a liver transplant candidate regarding the effect these complications have on the feasibility and timing of transplantation. Then the major medical problems that may occur as a result of liver transplantation will be reviewed.

\section{MEDICAL PROBLEMS PRIOR TO TRANSPLANTATION}

Despite advances in the application of liver transplantation. the requirements for candidacy have remained fairly constant (Table 1). An individual under consideration must have an irreversible, progressive liver disease such that death or unacceptable morbidity are the alternatives to

University of Pittsburgh School of Medicine, Pittsburgh, Pennsylvanin

This work was supported in part by grants NIDDKD DK32556 and NIAAA A A06(6)1.

Gastroenterology Clinics of North America-Vol. 17, No. 1. March 1988 